\title{
Bibliometrics and visualization analysis of China's Service Quality Development Trend
}

\author{
Lei $\mathrm{Xu}^{1, \mathrm{a}}$, Yuan $\mathrm{Ni}^{2, \mathrm{~b}}$, Pengfei $\mathrm{Han}^{3, \mathrm{c}}$,Teng Zhang ${ }^{4, \mathrm{~d}}$ \\ ${ }^{1}$ Beijing Information Science and Technology University School of Economics and Management Beijing, China \\ ${ }^{2}$ Beijing Information Science and Technology University School of Economics and Management Beijing, China \\ ${ }^{3}$ Beijing Information Science and Technology University School of Economics and Management Beijing, China \\ ${ }^{4}$ Beijing Information Science and Technology University School of Economics and Management Beijing, China
}

\begin{abstract}
From the aspect of bibliometrics and social network analysis, this paper studies the content characteristics and network evolution of service quality in China, form visual analysis charts and summarizes the research hotspots and development trends. Taking CNKI database as the data source, data mining and association analysis of sample data were carried out by means of manual judgment, keyword cooccurrence, bibliometric software BICOMB and Pajek. 872 related literatures were retrieved from 1999 to 2019 , and the tendency of the number of published papers in each year was close to the inverted U type. This study expands the application fields of bibliometrics and social network software, and analyzes the development trend of service quality. The theoretical and practical research on service quality has achieved rapid development in the past 20 years. The library service quality and service quality satisfaction have always gotten a high level of attention, and the characteristics of network platforms for service quality have gradually become apparent because of the development of the Internet and computer technology.
\end{abstract}

\section{Introduction and literature revieW}

With the development of China's economy and society, people put forward higher quality request for life, and service is increasingly valued by all walks of life. Since the 18th National Congress, the development of service industry has stepped into a new phase. The ratio of service industry in GDP has further raised, accounting for half of the national economy. There are many kinds of services and different attributes, so it is difficult to give a clearer definition and carry out a proper evaluation the service quality of various industries. In recent years, the number of research articles has been increasing, but there is a lack of summary articles on service quality in China. Therefore, this paper organizes and analyzes the study of service quality in China.

The concept of service quality was first put forward by Gronroos in 1982. He defined service quality as customer perceived quality. He believed that service quality should be embodied in service results and service process, that is, the technology contained in the process of customer's service acquisition and service acquisition ${ }^{[1]}$. Parasurama proposed the concept of gaps in 1988, and pointed out that service quality is the difference between customer's expected service quality level and customer's perceived service quality level ${ }^{[2]}$.A. Parasuraman, valarie a. Zeithaml and Leonard L. Berry (PZB, 1985) suggested 10 dimensions of service quality: reliability, ability, responsiveness, accessibility, politeness, credibility, communication, security, understanding and tangibility. In 1988, Parasuraman and other scholars put forward a five dimensions model of service quality: tangibleness, reliability, responsiveness, assurance and empathy. This model has been widely accepted and adopted by later generations $^{[3]}$.

Compared with foreign research, domestic research on service quality started late, and scholars have no unified understanding of the concept and definition of service quality. Wang Chunxiao believes that service quality is the product of the integration of the objective reality of service and the subjective feeling of customers, and it is composed of environmental quality, technical quality, emotional quality, relationship quality and communication quality ${ }^{[4]}$. According to Han Jinglun, the dimension of service quality reveals the aspects from which customers evaluate and perceive the service quality. The importance of service dimension in different industries and enterprises is different ${ }^{[5]}$.

Due to the rapid development of service industry and people's increasing willingness to serve, the research on service quality develops rapidly and involves many fields. Service industry is usually divided into living service industry, production service industry and public social service industry. In terms of the research on the quality of life service, namely tourism leisure, education guidance, housekeeping Hotel, etc. $\mathrm{Xu}$ Ronglin proposed a conceptual model of tourism service quality based on the perspective of employees, and constructed five potential variables, namely, working environment, staff life, work 
return, employee emotion and service quality, and conducted empirical research on Jiuzhaigou and Huanglong scenic spots ${ }^{[6]}$. Dong Jing discussed the relationship between multi market contact and enterprise service quality, and the regulatory role of institutional environment. His research results support the hypothesis of "mutual restraint" and enrich the theory of multi market contact and service quality ${ }^{[7]}$. In terms of production service quality, i.e. R \& D design, electronic information, logistics warehousing, business services, etc., Qin Xuelian summarized the connotation, characteristics and formation mechanism of supply chain logistics service quality, and reviewed the research on measurement of supply chain logistics service quality from the aspects of scale development and evaluation methods ${ }^{[8]}$. Zuo Wenming proposed a $\mathrm{B} 2 \mathrm{C}$ e-commerce service quality problem mining model based on internet word-of-mouth (WOM), which can discover the deficiencies in the service process and improve the service quality management ${ }^{[9]}$. In the research of public social services, such as medical education, public utilities, market supervision and so on, Bai Ruli empirically estimates the influencing factors of the service quality of wechat office account of University Libraries in Zhejiang Province, and puts forward some suggestions on how to improve the service quality of wechat office account ${ }^{[10]}$. Wanyan Dengdeng analyzed the quality gap of public digital culture service and its root causes, and put forward the strategies to improve the quality of public digital culture service ${ }^{[11]}$.

\section{2 data processing}

\subsection{Data Sources}

The retrieval time of this paper is March 20, 2020, and CNKI database provides the source of data. The key words are "service quality" and the subject is "service quality". The retrieval range is CSSCI, and 872 literatures are obtained. 9 non-conforming research contents and notices issued by the editorial department were screened out, and 863 valid documents were finally obtained.

According to the statistics of the number of thesis published in China in the past 20 years from 1999 to 2019, as shown in Fig. 1, it presents an inverted U-shape. Since the domestic research on service quality started late, the number of papers published has been at a low level from 1999 to 2006. A large number of articles on service quality have increased since 2007, nearly doubling compared with 2006. However, since 2017, the number of articles published has gradually declined. From 2007 to
2016, the number of published treatises increased by three times in the past nine years, indicating that the academic circles paid more attention to the research on service quality during this period. Therefore, according to the growth rate of the number of articles, this paper divides the research stage of service quality into three stages: 1999-2006, 2007-2016 and 2017-2019.

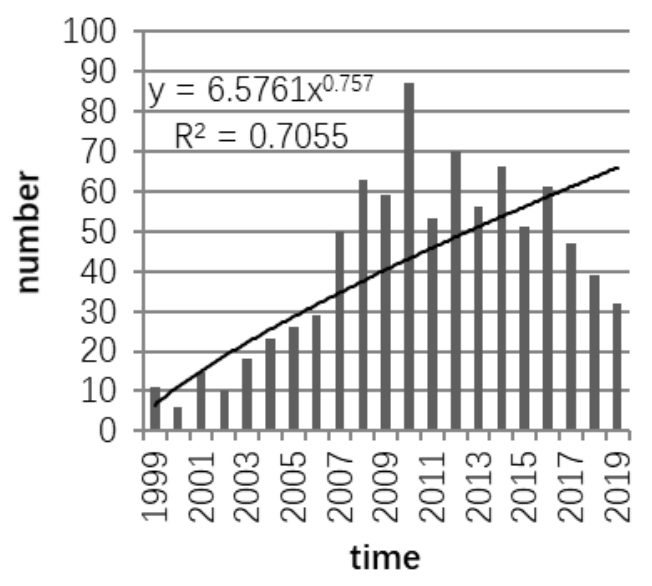

Figure 1. Statistics on statistics

In this paper, bibliometric software BICOMB is used to extract and count the key words in the three stages. Some high-frequency words appearing in the three stages are shown in TableI. The key words of the first stage (1999-2006) are service quality, library, customer satisfaction, etc. This stage is the initial phase of the development of the field, the theory is not perfect, the research on service quality is not enough attention, and the relevant literature is relatively small. However, the number of papers published has increased steadily, which shows that more and more observation has been paid to the research in this field. The key words in the second stage (2007-2016) are service quality, satisfaction, library, evaluation index, etc. This stage is a period of vigorous development in the field, and the number of published theses is increasing markedly. Scholars continue to pay attention to the service quality of the library, and pay more attention to the service quality evaluation. How to quantify the service quality and determine the evaluation index has become a new research area. The key words in the third stage (2017-2019) are service quality, customer satisfaction, mobile library, University Library, user perception, etc. At this stage, due to the rise of mobile Internet, the research on library service quality also follows the trend of the times, and the quality service of mobile library has become a new research object.

TABLE I. KEYWORD FREQUENCY

\begin{tabular}{|c|c|c|c|c|c|}
\hline \multicolumn{2}{|c|}{ The first stage } & \multicolumn{2}{c|}{ The second stage } & \multicolumn{2}{c|}{ The third stage } \\
\hline Keyword & $\begin{array}{c}\text { Freque } \\
\text { ncy }\end{array}$ & Keyword & $\begin{array}{c}\text { Freque } \\
\text { ncy }\end{array}$ & Key word & $\begin{array}{c}\text { Freque } \\
\text { ncy }\end{array}$ \\
\hline $\begin{array}{c}\text { Service } \\
\text { quality }\end{array}$ & 132 & Service quality & 587 & Service quality & 104 \\
\hline library & 22 & Satisfaction & 86 & $\begin{array}{c}\text { customer } \\
\text { satisfaction }\end{array}$ & 13 \\
\hline
\end{tabular}




\begin{tabular}{|c|c|c|c|c|c|}
\hline $\begin{array}{c}\text { customer } \\
\text { satisfaction }\end{array}$ & 21 & library & 58 & Mobile Library & 9 \\
\hline evaluate & 7 & $\begin{array}{c}\text { evaluating } \\
\text { indicator }\end{array}$ & 39 & $\begin{array}{c}\text { University } \\
\text { Library }\end{array}$ & 7 \\
\hline SERVQUAL & 5 & $\begin{array}{c}\text { University } \\
\text { Library }\end{array}$ & 24 & $\begin{array}{c}\text { User } \\
\text { perception }\end{array}$ & 5 \\
\hline $\begin{array}{c}\text { information } \\
\text { service }\end{array}$ & 4 & SERVQUAL & 24 & $\begin{array}{c}\text { User } \\
\text { experience }\end{array}$ & 5 \\
\hline
\end{tabular}

TABLE II. AUTHOR FREQUENCY

\begin{tabular}{|c|c|c|c|c|c|}
\hline \multicolumn{2}{|c|}{ The first stage } & \multicolumn{2}{c|}{ The second stage } & \multicolumn{2}{c|}{ The third stage } \\
\hline Author & $\begin{array}{c}\text { Frequ } \\
\text { ency }\end{array}$ & Author & $\begin{array}{c}\text { Frequ } \\
\text { ency }\end{array}$ & Author & $\begin{array}{c}\text { Frequ } \\
\text { ency }\end{array}$ \\
\hline Roman & 3 & Shi Guohong & 7 & $\begin{array}{c}\text { Song } \\
\text { Xueyan }\end{array}$ & 3 \\
\hline $\begin{array}{c}\text { Wen Biyan, } \\
\text { Wang } \\
\text { Chunxiao }\end{array}$ & 2 & Li Chunlan & 6 & Deng Jun & 3 \\
\hline Wang Ying & 2 & Su Lujun & 6 & Zhao Na & 2 \\
\hline $\begin{array}{c}\text { Zhang } \\
\text { Yuanfang }\end{array}$ & 2 & Su Qin & 5 & $\begin{array}{c}\text { Wang } \\
\text { Yuchao }\end{array}$ & 2 \\
\hline Feng Mei & 2 & Liu Jinyuan & 4 & Jin Xiaopu & 2 \\
\hline Wang pin & 2 & Ling Qian & 4 & $\begin{array}{c}\text { Shi } \\
\text { Guohong }\end{array}$ & 2 \\
\hline
\end{tabular}

Research trends of service quality can also be obtained from journals published in related literature. The highfrequency publication journals in the three stages are as follows. The first stage (1999-2006) was mainly published in the Library And Information Service, Tourism Tribune and other journals. The second stage (2007-2016) is mainly published in Journal of Intelligence, Library And Information Service. The third stage (2017-2019) is mainly published in Library And Information Service, Information Science and other journals. From the three stages, we can see that the largest number of publications is Library And Information Service. The journal belongs to the amphibious academic core journal of library and information science, and the comprehensive impact factor is 2.133 .

The authors of the three stages are indicate in TableII. The first stage (1999-2006) was published by Roman, Wen Biyan and Wang Chunxiao. The second stage (20072016) was published by Shi Guohong, Li Chunlan and others. The third stage (2017-2019) is mainly published by Song xueyan, Deng Jun and others. From the three stages, there are no outstanding field leaders in this field, and the amount of published papers is relatively balanced.

\subsection{Co-occurrence Coefficient Analysis}

Co-occurrence analysis is a method of content analysis. Aiming at a pair of phrases, the number of times they appear simultaneously in the same article is counted respectively to form a matrix of the common occurrence frequency of these words. Based on this matrix, the cluster analysis of these words is carried out ${ }^{[12]}$. Since service quality in China is a new research direction in the past two decades, the research content is relatively scattered, and there is no stable and mature system center. Therefore, keyword co-occurrence analysis can well reflect the focus and hot spots in the field of service quality research. Firstly, the frequency of high-frequency keywords in different stages of literature was counted, and then the co-occurrence matrix was obtained. According to the Ochiia coefficient method:

$$
\mathrm{I}_{\mathrm{ij}}=\frac{C_{i j}}{\sqrt{C_{i} \cdot C_{j}}}
$$

the co-occurrence coefficient of keywords was calculated. $\mathrm{I}_{\mathrm{ij}}$ is the co-occurrence coefficient between the keywords $\mathrm{i}$ and $\mathrm{j}, \mathrm{C}_{\mathrm{ij}}$ is the frequency of the co occurrence of the keywords $\mathrm{i}$ and $\mathrm{j}, \mathrm{C}_{\mathrm{i}}$ is the total number of times the keyword $i$ appears, and $C_{j}$ is the total number of times the keyword $\mathrm{j}$ appears.

\subsection{Social Network Analysis}

Social network analysis is a sociological research method formed on the basis of social network research. To study the characteristics of the network and its influence by analyzing the social network of the research object ${ }^{[13]}$. Computing the centrality of network is an important method of social network analysis. Centrality of network includes closeness centrality, degree centrality, betweenness centrality and eigenvector centrality. Centrality of network reflects the degree of nodes approaching centrality. In this paper, in order to compare the position of each keyword close to the center, the centrality of each keyword is calculated by closeness centrality, which is expressed by formula (2).

$$
C \mathrm{c}(\mathrm{vi})=\frac{\mathrm{N}-1}{\sum_{\mathrm{j}=1, \mathrm{j} \neq \mathrm{i}}^{\mathrm{N}} \mathrm{d}_{\mathrm{ij}}}
$$

$\mathrm{N}$ is the number of nodes in the network, and $\mathrm{D}_{\mathrm{ij}}$ is the shortest distance between node $\mathrm{V}_{\mathrm{i}}$ and node $\mathrm{V}_{\mathrm{j}}$. Network density indicates the tightness of nodes in the network, and generally decreases with the increase of network scale, which is expressed by formula (3). 


$$
A D=\frac{M}{N(N-1)}
$$

$\mathrm{M}$ is the number of network sides. The network clustering coefficient is the weighted average of the clustering coefficient of each node, which is also called transitivity. It represents the possibility that network nodes and neighbor nodes connect to the same node, which is expressed by formula (4).

$$
C C_{1}=\frac{2 E(\mathrm{v})}{G(v) \cdot[G(v)-1]}
$$

The nodes directly connected or containing one adjacent node are represented by $E(v)$, and $G(v)$ is the number of adjacent nodes of keyword v. Average degree reflects the dispersion of nodes, which is expressed by equation (5). Among them, $\mathrm{K}_{\mathrm{i}}$ is the node degree of node $\mathrm{V}_{\mathrm{i}}$. Software Pajek is used to calculate the density, network clustering coefficient and average degree of key network nodes.

$$
\bar{k}=\frac{1}{N} \sum_{i-1}^{N} k_{i}
$$

\section{RESULT ANALYSIS}

\subsection{Three Stage Analysis based on Ochiia Coefficient}

According to the statistical results of keywords, the cooccurrence matrix of high-frequency keywords is obtained. Then, the Ochiiia coefficient is calculated by using formula (1), and the co-occurrence coefficients of high-frequency keywords and "service quality", "customer satisfaction" and "satisfaction" in different stages are calculated. The results are shown in Table III. The following conclusions are drawn by analysis of the

\begin{tabular}{|c|c|c|c|c|c|c|c|c|c|c|c|}
\hline \multicolumn{2}{|c|}{ The first stage } & $\begin{array}{l}\text { Service } \\
\text { quality }\end{array}$ & $\begin{array}{c}\text { customer } \\
\text { satisfaction }\end{array}$ & \multicolumn{2}{|c|}{ The second stage } & $\begin{array}{l}\text { Service } \\
\text { quality }\end{array}$ & $\begin{array}{c}\text { customer } \\
\text { satisfaction }\end{array}$ & \multicolumn{2}{|c|}{ The third stage } & $\begin{array}{l}\text { Service } \\
\text { quality }\end{array}$ & $\begin{array}{c}\text { customer } \\
\text { satisfaction }\end{array}$ \\
\hline key word & frequency & \multicolumn{2}{|c|}{$\begin{array}{c}\text { Co-occurrence } \\
\text { coefficient }\end{array}$} & key word & frequency & \multicolumn{2}{|c|}{$\begin{array}{c}\text { Co-occurrence } \\
\text { coefficient }\end{array}$} & key word & frequency & \multicolumn{2}{|c|}{$\begin{array}{c}\text { Co-occurrence } \\
\text { coefficient }\end{array}$} \\
\hline library & 22 & 0.41 & 0 & library & 58 & 0.31 & 0.08 & $\begin{array}{l}\text { Mobile } \\
\text { Library }\end{array}$ & 9 & 0.26 & 0.09 \\
\hline evaluate & 7 & 0.23 & 0 & $\begin{array}{c}\text { evaluating } \\
\text { indicator }\end{array}$ & 39 & 0.25 & 0.05 & $\begin{array}{l}\text { University } \\
\text { Library }\end{array}$ & 7 & 0.26 & 0 \\
\hline SERVQUAL & 5 & 0.16 & 0.10 & $\begin{array}{c}\text { University } \\
\text { Library }\end{array}$ & 24 & 0.20 & 0.04 & $\begin{array}{c}\text { User } \\
\text { perception }\end{array}$ & 5 & 0.22 & 0 \\
\hline $\begin{array}{l}\text { information } \\
\text { service }\end{array}$ & 4 & 0.09 & 0 & SERVQUAL & 24 & 0.19 & 0.02 & $\begin{array}{c}\text { User } \\
\text { experience }\end{array}$ & 5 & 0.18 & 0 \\
\hline $\begin{array}{l}\text { Reader } \\
\text { service }\end{array}$ & 4 & 0.17 & 0 & $\begin{array}{c}\text { Customer } \\
\text { loyalty }\end{array}$ & 20 & 0.18 & 0.31 & $\begin{array}{l}\text { influence } \\
\text { factor }\end{array}$ & 4 & 0.20 & 0 \\
\hline service & 3 & 0.15 & 0 & evaluate & 18 & 0.175 & 0.05 & $\begin{array}{l}\text { Wechat } \\
\text { public } \\
\text { account }\end{array}$ & 4 & 0.15 & 0.14 \\
\hline
\end{tabular}
data in the Table III.

TABLE III. KEYWORD CO-OCCURRENCE COEFFICIENT

There is a big gap between the co-occurrence coefficient of each keyword and service quality in the first stage from 1999 to 2006 . The co-occurrence coefficient of library is as high as 0.41 , which shows that the main research field of scholars is in library. In the field of library service quality research, information service and reader service are also the extension of this research field. In addition, using SERVQUAL scale model to measure customer satisfaction has become a new research direction.

In the second stage of 2007-2016, the co-occurrence coefficient of each keyword and service quality has a small gap, and the co-occurrence coefficient of library and evaluation has decreased significantly. However, with the deepening of research, quantifying the evaluation content and constructing evaluation indicators has become a hot research field. In addition, the research on the service quality of university library has become a research hotspot. Compared with the first stage, the co-occurrence coefficient of each keyword and satisfaction increased, indicating that the research on satisfaction in this field has gradually attached importance, and exploring people's satisfaction with service quality has become the main research direction in this stage. The co-occurrence coefficient of satisfaction and customer loyalty is higher, which indicates that loyalty is a major aspect of satisfaction research.

In the third stage from 2017 to 2019, the cooccurrence coefficient of each keyword and service quality is relatively average, but the co-occurrence coefficient of university library is slightly increased. User perception, user experience and influencing factors have become the emerging research direction. With the rise of mobile Internet, mobile library and Wechat Office Account also expand the research field of service quality. The co-occurrence coefficient of customer satisfaction and service quality in this stage is significantly lower than that in the second stage, which indicates that the research on customer satisfaction in traditional fields has become saturated, but there is still space for research in emerging fields such as mobile library and Wechat Office Account.

\subsection{Three Stage Analysis based on Centrality}

Using Software Pajek, the keywords with threshold higher than 2 were selected in the first stage (1999-2006) and the third stage (2017-2019), and the keywords with threshold greater than 3 were selected in the second stage (20072016). The centrality of each keyword in different stages was calculated, and the centrality $\mathrm{Cc}$ (vi) was divided into 
three levels: (1)core node: $\mathrm{Cc}(\mathrm{vi}) \geq 0.54$; (2) intermediate node: $0.54 \geq \mathrm{Cc}(\mathrm{vi}) \geq 0.52$; (3)edge node: $\mathrm{CC}(\mathrm{Vi}) \leq 0.52$. On this basis, draw the keyword relationship link network, as shown in Fig. 2, 3. The deeper the node color, the higher centrality. - indicates the core node, - indicates the intermediate node, and $\bullet$ indicates the edge node.

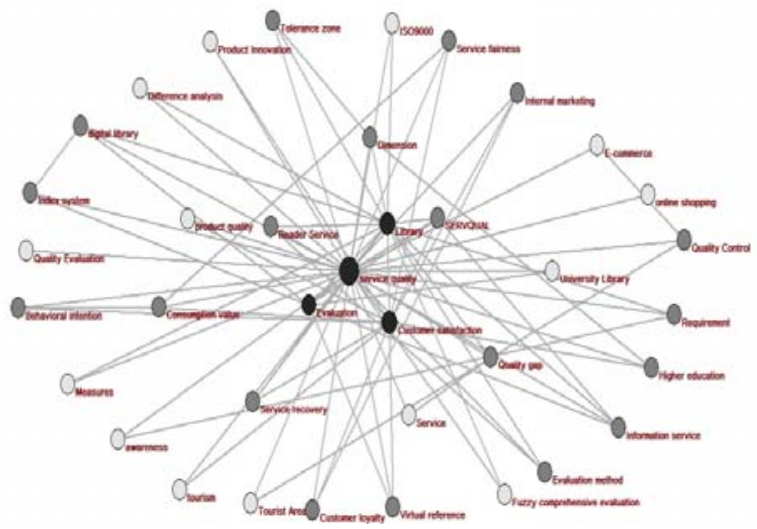

Figure 2. Keywords central hierarchical distribution network (stage 1)

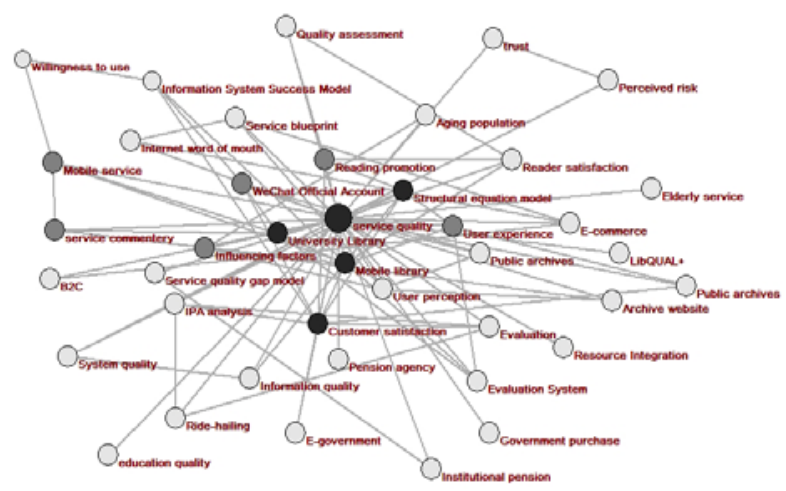

Figure 3. Keywords central hierarchical distribution network (stage 3)

Stage 1: 1999-2006

As is seen in Fig. 2, there are 37 keywords with word frequency greater than or equal to 2 in this stage, including 4 core nodes. The core keywords are service quality, library, customer satisfaction and evaluation. Their centralities are $1.00,0.63,0.60,0.56$ respectively and service quality was in the center. There are 19 nodes in the middle layer, accounting for $51.4 \%$ of the total, and 14 nodes at the edge, accounting for $37.8 \%$ of the total. Stage 1 can be concluded that the nodes in the middle layer account for a large proportion in this stage by the analysis, and the service quality, customer satisfaction, evaluation, SERVQUAL and information service are all highly concerned research from the analysis results of keyword frequency and centrality.

\section{Stage 2: 2007-2016}

In this stage, 101 keywords with word frequency greater than or equal to 3 are obtained, including 9 core nodes. The core keywords are service quality, satisfaction, library, evaluation index, influencing factors, analytic hierarchy process, etc., which the centralities are 1.00, $0.63,0.58,0.56,0.54$ and 0.54 . Service quality is still at the absolute core. There are 12 nodes in the intermediate layer, accounting for $11.9 \%$ of the total, and 80 nodes at the edge, accounting for $79.2 \%$ of the total. Through the above analysis, the proportion of intermediate layer nodes is significantly reduced, and the proportion of edge nodes is significantly increased in the second stage. It can be seen that the scope of service quality research has significantly widen, and the research direction has become diversified and enriched. The word frequency of influencing factors and analytic hierarchy process is 18 and 10 respectively, but the centralities are both 0.54 . Although the frequency of nodes is relatively low, the link degree with other high-frequency keywords is high.

Stage 3: 2017-2019

As is seen in Fig. 3, there are 41 keywords with word frequency greater than or equal to 2 in this stage, including 5 core nodes. The core keywords are service quality, mobile library, customer satisfaction, University Library, and structural equation model, of which the centrality are $0.95,0.58,0.57,0.54,0.54$, and 0.53 . Service quality is still at the absolute core. There are 6 nodes in the intermediate layer, accounting for $14.6 \%$ of the total number, and 30 nodes at the edge, accounting for $73.2 \%$ of the total. We can see that the research field of service quality has been further widened, such as Wechat Office Account, pension service and other emerging service fields. Although the keyword frequency of user perception and user experience is higher, it is not as good as structural equation model linking with other highfrequency keywords.

\subsection{Three Stage Analysis based on Network Characteristics}

Software Pajek is used to calculate the density, network clustering coefficient and average degree of keywords in three stages. The results are shown in Table IV. The keyword density of the first stage is the largest, which indicates that the keyword density in the first stage is relatively high. The network clustering coefficient shows the degree of connection between a keyword and its adjacent keywords in a stage, which shows that the key words in the three stages are not closely related. The average degree reflects the dispersion of research points. The average degree of nodes in the first and third stages are remarkably lower than in the second stage, so the research points in these two stages are relatively scattered.

TABLE IV. NETWORK CHARACTERISTIC INDEX

\begin{tabular}{|c|c|c|c|}
\hline $\begin{array}{c}\text { Network } \\
\text { characteristic } \\
\text { index }\end{array}$ & $\mathbf{1}$ & $\mathbf{2}$ & $\mathbf{3}$ \\
\hline Density & 0.144 & 0.080 & 0.131 \\
\hline $\begin{array}{c}\text { Network Clustering } \\
\text { Coefficient }\end{array}$ & 0.180 & 0.167 & 0.196 \\
\hline Average Degree & 10.649 & 16.020 & 10.780 \\
\hline
\end{tabular}




\section{CONCLUSION}

The research on service quality in China began in the 1990s, and the research boom period in this field was from 2007 to 2016, and it decreased slightly after 2017. After more than 20 years of research and development, the theoretical and practical research on service quality has made great progress. From the research and analysis of this paper, the research topics of service quality are relatively broad, and the research methods are relatively rich. Among them, the service quality research of library is in the core position, and there are gradually emerging research directions of university library, mobile library, reader service, information service and so on. In addition, with the development of the service industry and the improvement of people's service requirements, it has become the main research direction to explore the customer's satisfaction, the evaluation, and the influencing factors of service quality. Because the service quality involves a wide range of fields, and the research in each field has not yet unified system, the development of service quality research is uneven and lack of close contact. In the future, with the development of AI, machine learning, cloud computing and other technologies, there will be new opportunities for the research direction and research methods of service quality, and the research of service quality will usher in more opportunities and challenges.

\section{Acknowledgment}

Fund Project: Beijing Youth Top Talent Cultivation Project (CIT\&TCD 20180405); QinXin talent program (QXTCPC201706); Beijing Association for Science and Technology Young Talents Support Plan; 2020 Promotion of College Connotation Development Project "Research on the Evaluation of Cultural Value Added of Created Products Under the Network Platform Environment" (5112011042).

\section{References}

1. Gronroos C. A Service Quality Model and Its Marketing Implications [J]. European Journal of Marketing, 1984 (4).

2. Parasuraman A, Zeithaml V A, Berry L L. SERVQUAL: A Multiple-ItemScale for Measuring
Consumer Perceptions of Service Quality [J]. Journalof Retailing, 1988 (1).

3. Ge Yating, Jiang Lin, is Lina. Research on the improvement of online tourism service quality based on SERVQUAL model [J]. Electronic Commerce, 2020(02): 4-6.

4. Wang Chunxiao and Cai Haoran. Service Marketing and Service Quality Management [M]. Guangzhou: Sun Yat-sen University Press. 1996.

5. Han Jinglun, Dong Jun. Evaluation and Management of Customer Perceived Service Quality [M]. Tianjin: Nankai University Press. 2006.

6. Xu Ronglin, Wang Jianqiong. An Empirical Study on Scenic Tourism Service Quality Based on the Employee Perspective[J]. Tourism Science, 2016, 30(04): 86-94.

7. Dong Jing, Wang Yajuan. Multi-market contact and service quality of China's economic hotel chains[J]. Economic Management, 2019, 41(11): 157-173.

8. Qin Xuelian, Liu Zhixue. Review and Prospect of Research on Supply Chain Logistics Service Quality[J]. Journal of Management, 2018, 15(11): 1731-1738.

9. Zuo Wenming, Chen Huaqiong, Zhang Zhenpeng. B2C e-commerce service quality management based on Internet word of mouth $[\mathrm{J}]$. Management Review, 2018, 30(02): 94-106.

10. Bai Ruli, Tan Wenting. Research on the Influencing Factors of Service Quality of University Library's WeChat Public Platform[J]. Library Theory and Practice, 2019(09): 37-40.

11. Wan Yan Deng Deng, Zhang Yannan. Public digital cultural service quality improvement strategyService quality gap model perspective[J]. Library Science Research, 2019(14): 77-81+97.

12. Zhang Yibing, Ge Xinquan, Wang Zongshui. Analysis of the development trend of brand marketing in my country from the perspective of literature analysis $[\mathrm{J}]$. Business Economics Research, 2019(15): 64-67.

13. Wang Zongshui, Zhao Hong, Liu Yu, Qin Xuzhong. The evolution, development and application of social network research paradigm-Based on the analysis of Chinese social science citation data from 1998 to $2014[\mathrm{~J}]$. Journal of Information, 2015, 34(12): 1235-1245. 